\title{
Amygdaloid involvement in the defensive behavior of mice exposed to the open elevated plus-maze
}

\author{
Tatiani Sorregotti ${ }^{\mathrm{a}, \mathrm{b}}$, Ana Cláudia Cipriano ${ }^{\mathrm{a}, \mathrm{b}}$, Fábio Cardoso $\mathrm{Cruz}^{\mathrm{c}}$, \\ Diego Cardozo Mascarenhas ${ }^{\mathrm{a}, \mathrm{b}}$, Robert John Rodgers ${ }^{\mathrm{d}}$, Ricardo Luiz Nunes-de-Souza ${ }^{\mathrm{a}, \mathrm{b}, *}$ \\ a Joint Graduate Program in Physiological Sciences, UFSCar/UNESP, São Carlos, SP, 13565-905, Brazil \\ b Laboratory of Neuropsychopharmacology, School of Pharmaceutical Sciences, Univ. Estadual Paulista, UNESP, 14800-903, Araraquara, SP, Brazil \\ c Department of Pharmacology, Federal University of São Paulo, 04023-901, São Paulo, SP, Brazil \\ d School of Psychology, University of Leeds, Leeds, LS29JT, UK
}

\section{A R T I C L E I N F O}

\section{Keywords:}

Open elevated plus maze

Amygdala

Immunohistochemistry

Cobalt chloride

Defensive behavior

Mice

\begin{abstract}
A B S T R A C T
Previous studies have shown that the exposure to an open elevated plus maze (oEPM, an EPM with all four open arms) elicits fear/anxiety-related responses in laboratory rodents. However, very little is known about the underlying neural substrates of these defensive behaviors. Accordingly, the present study investigated the effects of chemical inactivation of the amygdala [through local injection of cobalt chloride $\left(\mathrm{CoCl}_{2}\right.$ : a nonspecific synaptic blocker)] on the behavior of oEPM-exposed mice. In a second experiment, the pattern of activation of the basolateral (BLA) and central (CeA) nuclei of the amygdala was assessed through quantification of Fos protein expression in mice subjected to one of several behavioral manipulations. To avoid the confound of acute handling stress, 4 independent groups of mice were habituated daily for 10 days to an enclosed EPM (eEPM) and, on day 11 prior to immunohistochemistry, were either taken directly from their home cage (control) or individually exposed for $10 \mathrm{~min}$ to a new clean holding cage (novelty), an eEPM, or the oEPM. An additional group of mice (maze-naïve) was not subjected to either the habituation or exposure phase but were simply chosen at random from their home cages to undergo an identical immunohistochemistry procedure. Results showed that amygdala inactivation produced an anxiolytic-like profile comprising reductions in time spent in the proximal portions of the open arms and total stretched attend postures (SAP) as well as increases in time spent in the distal portions of the open arms and total head-dipping. Moreover, Fos-positive labeled cells were bilaterally increased in the amygdaloid complex, particularly in the BLA, of oEPM-exposed animals compared to all other groups. These results suggest that the amygdala (in particular, its BLA nucleus) plays a key role in the modulation of defensive behaviors in oEPM-exposed mice.
\end{abstract}

\section{Introduction}

Animals exhibit various neurovegetative (e.g., increased blood pressure, defecation) and behavioral (e.g., freezing, flight) responses when confronted with innate or learned danger stimuli. These defensive responses can be detected through animal tests for anxiety. For instance, rodents exposed to predators $[1,2]$, novelty $[3,4]$ or open environments [5-9] display a range of defensive reactions (e.g., escape, avoidance, freezing and antinociception).

The open elevated plus maze (oEPM) is a type of highly aversive environment that has been used to study the neurobiology of fear-induced antinociception [8,10-12] and defensive behaviors [9]. This new paradigm is similar to that described by Lister (1987) [6], except that it comprises four open arms, instead of two open and two closed arms.
Exposure of mice to the oEPM enhances plasma corticosterone titers [8] and elicits defensive behaviors such as stretched attend postures, flatback approach, and head dipping [9]. Furthermore, systemic injection of alprazolam, a potent benzodiazepine [13], attenuates defensive behavior in mice exposed to this test, suggesting that the procedure is sensitive to anxiolytic/panicolytic drugs [9]. At present, very little is known about the neural substrates that modulate the defensive behavior of animals exposed to the oEPM. However, it has been reported that chemical lesions of dorsal or ventro-lateral portions of the periaqueductal grey matter (dPAG or vlPAG), components of midbrain defense circuitry [14], do not change oEPM-induced antinociception $[12,15]$, a type of fear/anxiety-induced pain inhibition.

Cellular and functional studies have repeatedly demonstrated that the amygdaloid complex plays a crucial role in the modulation of fear

\footnotetext{
* Corresponding author at: Laboratory of Neuropsychopharmacology, School of Pharmaceutical Sciences, Univ. Estadual Paulista, UNESP, 14800-903, Araraquara, SP, Brazil.

E-mail address: souzarn@fcfar.unesp.br (R.L. Nunes-de-Souza).
} 
and anxiety behaviors. Previous findings have shown that this forebrain area receives and processes aversive stimuli $[16,17][$ e.g.,16,17]. The amygdala comprises a set of nuclei, with complex inter- and intra-nuclear connections and which are subdivided into three main groups: the basolateral, corticomedial and centromedial groups [review: 17]. Previous studies have shown that these amygdaloid subnuclei are differentially involved in the modulation of defensive behaviors $[16,18,19]$. For example, electrolytic lesion specifically of the central nucleus (CeA) and basolateral nucleus (BLA) of the amygdala attenuate fear-related responses [review: 17]. Furthermore, Tanimoto et al. [19] demonstrated that bilateral chemical lesions of the BLA or CeA decrease conditioned place aversion in rats induced by plantar injection of formalin. In addition, cellular imaging of immediate early genes (IEG), such as c-fos, zif268, and arc, has also been used to map the neuronal substrate involved in behavior [20-23]. The protein Fos has been the most commonly used IEG marker of neuronal activity in behavioral research, including studies on fear and anxiety [24]. For instance, increased Fos expression has been identified in the amygdala of animals exposed to a conventional EPM [25-29]. Together, this body of evidence suggests that the amygdala might play a role in the modulation of defensive reactions displayed by mice during the exposure to the oEPM.

Although the amygdala is a bilateral structure, previous studies have revealed a degree of functional lateralization in the modulation of emotional responses in animals [30] and humans [31]. For example, Baker and Kim (2004) [30] found that the right amygdala exerts a strong role in the control of contextual fear conditioning in rats. Briefly, electrolytic lesions of the right (but not the left) amygdala decreased freezing behavior in rats exposed to the fear-associated context. In contrast, Tran and Greenwood-Van Meerveld (2012) [32] showed a lack of hemispheric lateralization of the CeA in the control of corticoidmediated anxiety-like behavior assessed in rats exposed to the EPM. These findings suggest the potential importance of hemispheric lateralization in the role of the amygdala in the modulation of defensive behavior of animals exposed to threatening situations, such as the oEPM.

Here, we investigated (i) the effects of chemical inactivation (through local injection of cobalt chloride $\left(\mathrm{CoCl}_{2}\right)$, an nonspecific synaptic blocker [33]) of the amygdala on the behavior of mice exposed to the oEPM; and (ii) the pattern of neuronal activation of the left and right amygdaloid complex and of the BLA and CeA subnuclei through quantification of Fos protein expression in mice exposed to the oEPM versus a number of important control conditions, including an enclosed EPM (eEPM, an EPM with four enclosed arms; control situation) and a non-maze novel environment (new cage). Basal Fos protein expression was also recorded in maze-naïve mice. This study therefore sought to clarify the role of the amygdala in the modulation of the defensive behavior of animals exposed to the oEPM and to further explore this new paradigm as a potential tool for research on the neurobiology of fear/anxiety.

\section{Materials and methods}

\subsection{Subjects}

Subjects were adult male Swiss mice (Univ. Estadual Paulista UNESP, SP, Brazil) weighing 25-35 $g$ at testing. They were housed in groups of 5 per cage $(33 \times 15 \times 13 \mathrm{~cm})$ and maintained under a normal $12 \mathrm{~h}$ light cycle (lights on at 7 a.m.) in a temperature $\left(23 \pm 1^{\circ} \mathrm{C}\right.$ ) controlled environment. Food and water were freely available, except during the brief test periods. All mice were experimentally naive, and experimental sessions were performed during the light phase of the cycle $(09.00 \mathrm{~h}-16.00 \mathrm{~h})$. The experimental protocols were approved by the Research Ethics Committee of the School of Pharmaceutical Sciences of the Universidade Estadual Paulista - UNESP (CEUA number 14/2014).

\subsection{Drug}

Cobalt chloride $\left(\mathrm{CoCl}_{2}\right.$; Sigma-Aldrich, Brazil) was dissolved in $0.9 \%$ physiological saline solution which alone served as control solution. The dose of $1.0 \mathrm{mM}$ of $\mathrm{CoCl}_{2}$ was based on previous studies $[34,35]$, and the total volume of injection within the amygdala was $0.1 \mu \mathrm{L}$.

\subsection{Surgery and microinjection}

Mice were bilaterally implanted with 7-mm stainless-steel guide cannulae (26-gauge; Insight Equipamentos Científicos Ltda) under ketamine and xylazine anaesthesia (100 mg/kg and $10 \mathrm{mg} / \mathrm{kg}$ i.p.). Guide cannulae, targeted $1.0 \mathrm{~mm}$ dorsal to the amygdala, were fixed to the skull using dental acrylic and jeweler's screws. Stereotaxic coordinates for the amygdala, based on Paxinos and Franklin (2001) [36] and a previous study in our laboratory [37], were $1.1 \mathrm{~mm}$ posterior to bregma, $3.1 \mathrm{~mm}$ lateral to the midline and $3.7 \mathrm{~mm}$ ventral to the skull surface. A dummy cannula (33-gauge stainless-steel wire; Fishtex Indústria e Comércio de Plásticos Ltda), inserted into each guide-cannula at the time of surgery, served to reduce the incidence of occlusion. At the end of the stereotaxic surgery, each mouse received an intramuscular injection of penicillin-G benzathine (Pentabiotic, $56.7 \mathrm{mg}$ / $\mathrm{kg}$ in a $0.1 \mathrm{~mL}$ volume; Fort Dodge, Campinas, SP, Brazil) and a subcutaneous injection of the anti-inflammatory analgesic Banamine $(3.5 \mathrm{mg} / \mathrm{kg}$ flunixin meglumine, Intervet Schering-Plough, Rio de Janeiro, RJ, Brazil, in a volume of $0.3 \mathrm{~mL}$ ).

Five days after following surgery, solutions were injected into the amygdala by microinjection units (33-gauge stainless steel cannulae; Insight Equipamentos Científicos Ltda), which extended $1.0 \mathrm{~mm}$ beyond the tip of each guide cannula. Each microinjection unit was attached to a $2 \mu \mathrm{L}$ Hamilton microsyringe via polyethylene tubing (PE10 ), and administration was controlled by the experimenter at a rate of $0.1 \mu \mathrm{L}$ (volume injected) over a period of approximately $20 \mathrm{~s}$. The microinjection procedure consisted of gently restraining the animal, removing the dummy cannulae, inserting the injection units, infusing the solution, and keeping the injection units in situ for a further $60 \mathrm{~s}$. Confirmation of successful infusion was obtained by monitoring the movement of a small air bubble in the PE-10 tubing.

\subsection{Apparatus}

The open elevated plus-maze (oEPM) is closely similar to the standard EPM (EPM) described by Lister (1987) [6] except that it has four open $(30 \times 5 \times 0.25 \mathrm{~cm})$ arms, raised $38.5 \mathrm{~cm}$ above floor level on a wooden pedestal. Each arm of the oEPM was divided into two sections, which were designated as proximal $(10 \times 5 \mathrm{~cm})$ and distal [medial and end of the arms $(20 \times 5 \mathrm{~cm})]$ portions relative to the central square $(5 \times 5 \mathrm{~cm})$ [for details, see 9]. In Experiment 2, amygdaloid c-fos activation in response to oEPM exposure was contrasted with exposure to an enclosed elevated plus-maze (eEPM; four enlcosed arms; $30 \times 5 \times 15 \mathrm{~cm}$; raised $38.5 \mathrm{~cm}$ above floor level) and an unfamiliar, clean home cage $(33 \times 15 \times 13 \mathrm{~cm})$.

\subsection{Procedure}

All behavioral tests were conducted during the light phase of the light/dark cycle, under the illumination of a 100-W light bulb (50 Lux on the floor of the apparatus).

\subsubsection{Experiment 1}

2.5.1.1. Effects of amygdala inactivation on the behavior of mice exposed to the oEPM. In order to investigate the role of the amygdala in the modulation of defensive behavior of mice exposed to the oEPM, each mouse received a bilateral intra-amygdala injection of saline or $\mathrm{CoCl}_{2}$ $(1.0 \mathrm{mM})$ and, after $10 \mathrm{~min}$, was individually placed on the central 
square (always facing the same arm) and allowed to explore the oEPM freely for $10 \mathrm{~min}$. Between each test, the apparatus was cleaned with ethanol $20 \%$ and dried clothes. All sessions were recorded by a vertically mounted camera linked to a monitor and DVD recorder.

2.5.1.2. Behavioral analysis. Test DVDs were scored blind by a highly trained observer (intrarater reliability $\geq 0.90$ ) using the software " $\mathrm{X}$ plo-rat 2005", developed by Dr. Morato's Group, at the Faculdade de Filosofia, Ciências e Letras de Ribeirão Preto, University of São Paulo. The behavioral parameters comprised both spatiotemporal and ethological measures. Spatiotemporal measures were the frequency of entries and time spent on the central platform and in each section (proximal, distal) of the arms. Ethological measures comprised total stretched attend postures (SAP; exploratory posture in which the body is stretched forward then retracted to the original position without any forward locomotion), total flat back approach (s) (FBA; time spent slowly moving forward with the body stretched), and total head-dips (HD; an exploratory behavior in which the animal scans over the sides of the maze towards the floor) [9,38-40].

2.5.1.3. Histology. At the end of testing, all animals received an infusion of 1\% Evans blue (according to the microinjection procedure described above, on section 2.3) prior to anesthetic overdose. Their brains were removed, coronal sections cut using a cryostat microtome (Leica CM 1850), and injection sites histologically verified through reference to the atlas of Paxinos and Franklin [36]. Slices were stained by the cresyl-violet technique. Data from animals with injection sites outside the amygdala were excluded from the study.

\subsubsection{Experiment 2}

2.5.2.1. Amygdaloid fos activation in response to the oEPM. This experiment examined the pattern of amygdala activation in mice exposed either to the oEPM or a number of control conditions. The procedure for 4 groups of mice involved habituation and exposure phases. The habituation phase was used to avoid confounds arising from acute handling stress. During habituation, each subject was exposed for a 10-min period daily over 10 consecutive days to an eEPM. In contrast to the standard EPM, in which the two open arms are sources of threat, the totally enclosed EPM was selected as a control condition in order to create a relatively safe environment. During the exposure phase (Day 11), subjects were either taken from their home cage (control group) or individually exposed to the eEPM, a novel environment (unfamiliar clean home cage) or oEPM for $10 \mathrm{~min}$. Mazenaïve animals were randomly chosen from their home cages to undergo the same immunohistochemistry protocol. Ninety minutes after the exposure to the novel home cage, eEPM or oEPM, animals were deeply anesthetized, perfused transcardially with PBS followed by a solution of $4 \%$ paraformaldehyde and brains removed for immunohistochemistry. Control and maze-naïve mice were also deeply anesthetized and perfused immediately after they had been removed from their home cages.

2.5.2.2. Immunohistochemisty. Brains were removed and left overnight in a solution of $30 \%$ sucrose in $0.1 \mathrm{M}$ phosphate buffer saline (PBS) at $4{ }^{\circ} \mathrm{C}$. The brains were then frozen and three series of $35 \mu \mathrm{m}$ sections were cut with a cryostat microtome (Leica CM 1850) and one of the series was processed for immunohistochemistry. Slices was washed three times (10 min each) in PBS at room temperature on a shaker and was placed into blocking buffer (normal goat serum $3 \%$ and Triton X$1000.25 \%$ in PBS) for one hour at room temperature. After blocking, slices were incubated overnight with an anti-Fos antiserum raised in rabbit (Cell Signaling Technology, Danvers, MA, USA) at a dilution of 1:2000. Slices were again washed three times and incubated in a solution of biotinylated goat anti-rabbit IgG (Vector Laboratories, Burlingame, CA, USA) at dilution of 1:400 for $2 \mathrm{~h}$ and then placed in the mixed avidin-biotin horseradish peroxidase (HRP) complex solution (ABC Elite Kit; Vector Laboratories) for $1 \mathrm{~h}$. Immunoreactivity for Fos was revealed by the addition of the chromogen diaminobenzidin (DAB, 0.02\%, Sigma-Aldrich, Brazil), and hydrogen peroxide $(0.04 \%)$ and was visualized as a brown insoluble reaction product inside neuronal nucleus after $8 \mathrm{~min}$. The reaction was stopped by washing in PBS. Sections were mounted on gelatin-coated slides, and then dehydrated and coverslipped with Permount (Sigma-Aldrich, Brazil). The number of Fos immunoreactive neurons in the BLA and CeA of each hemisphere were counted using an optic microscopic (Zeiss Axioskop 2) coupled with a camera and the Axio Vision Rel. Zeiss software was used to quantify Fos-positive labelling.

\subsubsection{Statistical analysis}

All data were initially subjected to Levenés test for homogeneity of variance. Data from the two independent treatment groups in Experiment 1 were subjected to Student's $t$-tests. Data from Experiment 2 were subjected to a three-factor independent analysis of variance (ANOVA), [factor 1 (sub nuclei); factor 2 (condition); factor 3 (hemisphere)]. Where indicated by a significant ANOVA, data were further analyzed by Bonferroni's multiple range test. In all cases, $\mathrm{p} \leq 0.05$ was required for significance.

\section{Results}

\subsection{Experiment 1}

\subsubsection{Histology}

Fig. 1 shows a brain section based on the Paxinos and Franklin Atlas (2001) [36], indicating a schematic representation of the amygdala (left), and a photomicrograph of a coronal section of a representative subject, showing an injection site in the amygdala of the mouse (right). Histology confirmed that $82 \%$ of the microinfusion sites were in the basolateral (lateral + basal nuclei) nucleus (see Fig. 1) and $8 \%$ were in the central amygdala.

\subsubsection{Amygdala inactivation in the oEPM}

Fig. 2 shows the effects of intra-amygdaloid injection of $\mathrm{CoCl}_{2}$ on the behavioral profile of mice exposed to the oEPM. Student's $t$-tests revealed that amygdala inactivation decreased time spent in the proximal portions of the open arms $\left[t_{(17)}=2.97 ; \mathrm{p}<0.05\right]$ and total SAP $\left[t_{(17)}=2.17 ; \mathrm{p}<0.05\right]$ while increasing time spent in the distal portions of the open arms $\left[t_{(17)}=-2.60 ; \mathrm{p}<0.05\right]$ and total headdipping $\left[t_{(17)}=-3.06 ; \mathrm{p}<0.05\right]$. Importantly, no other behavioral parameter was significantly changed by intra-amygdala injection of $\mathrm{CoCl}_{2}$ in mice exposed to the oEPM.

\subsection{Experiment 2}

\subsubsection{Immunohistochemistry}

Fig. 3A shows a coronal brain slice of a representative subject exposed to the oEPM indicating, on the left, a rectangle showing the amygdaloid complex and, on the right, the basolateral (BLA) and central (CeA) nuclei in which the Fos-labeled cells were particularly increased. Fig. 3B shows the number of Fos-labeled cells in the CeA and BLA of both hemispheres in mice exposed to the five different test conditions (maze-naïve, home cage control, and novelty-, oEPM- or eEPM-exposed). Except for the hemisphere factor which was non-significant $\left(F_{1,56}=1.09\right.$, NS), three-way ANOVA yielded significance $(\mathrm{p}<0.05)$ for sub nuclei $\left(F_{1,56}=15.97\right)$ and condition $\left(F_{4,56}=41.67\right)$, as well as all interactions; nuclei $\times$ hemisphere $\quad\left(F_{1,56}=4.12\right)$; nuclei $\times$ condition $\quad\left(F_{4,56}=7.36\right)$; condition $\times$ hemisphere $\left(F_{4,56}=2.67\right)$; nuclei $\times$ hemisphere $\times$ condition $\left(F_{4,56}=4.88\right)$. Bonferroni's multiple range test revealed an increased number of Fos-positive cells in the BLA of both hemispheres in oEPMexposed animals. More specifically, oEPM-exposed mice displayed a higher number of Fos-stained cells in the right BLA compared to all other 


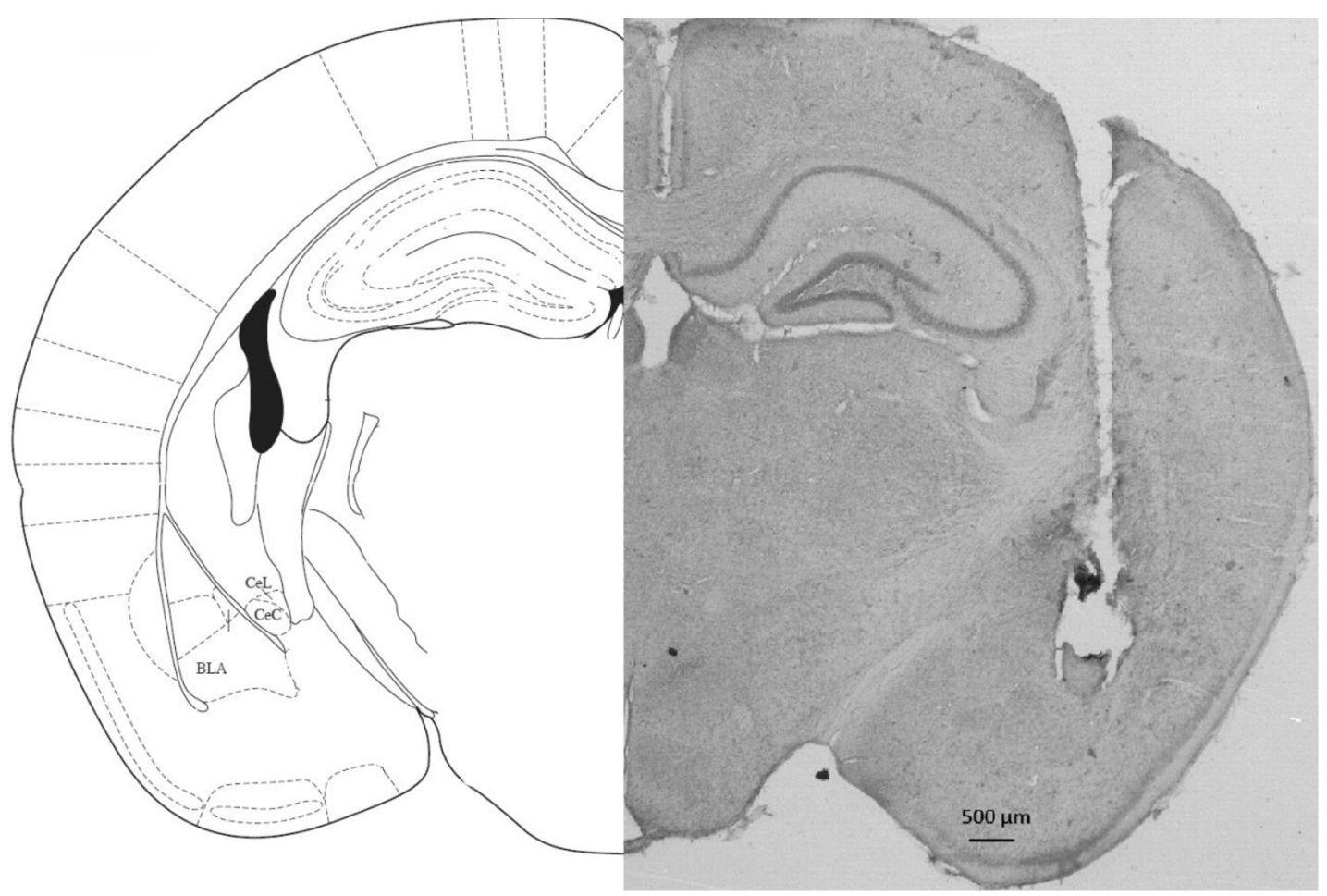

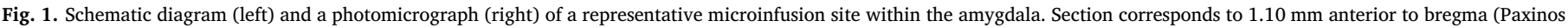
and Franklin, 2001).

groups (*p $<0.05$ ) and a higher number of Fos-stained cells in the left BLA compared to maze-naïve- and novelty-exposed mice (\#p < 0.05). In direct contrast, oEPM exposure did not significantly alter Fos expression in the CeA of either hemipshere when compared with maze-naïve or home cage control conditions. Interestingly, however, oEPM-exposed mice had a higher number of Fos-labeled cells in the left CeA compared to noveltyexposed mice. Moreover, both oEPM- and eEPM-exposed mice had an increased number of Fos-stained cells in the right CeA compared to novelty-exposed mice $(\$ p<0.05)$. Importantly, there were no hemispheric differences between Fos-labeled cells in the BLA or CeA of animals exposed to any condition ( $\mathrm{p}>0.05$ ).

\section{Discussion}

The results of the present study show that chemical inactivation of the amygdala leads to an anxiolytic-like profile in mice exposed to the oEPM, comprising reductions in time spent in the proximal portions of the open arms and total SAP as well as increases in time spent in the distal areas of the open arms and total head-dips. The involvement of the amygdala in the control of defensive behavior in the oEPM was further indicated through quantification of Fos expression in the BLA and CeA. In brief, relative to virtually all other conditions, oEPM exposure markedly increased the number of Fos-labeled cells within the BLA of both hemispheres. In contrast, oEPM (and to a lesser extent eEPM) exposure modestly increased the number of Fos-stained cells within the CeA when compared with the novelty condition only.

Experiment 1 showed that amygdala inactivation through local microinjection of $\mathrm{CoCl}_{2}$ decreased time proximal and total SAP, and increased time distal and total head-dipping in mice exposed to the oEPM. In this context, it is important to note that there was no treatment effect on total entries, confirming that the pattern of behavioral change seen in response to amygdaloid inactivation cannot be attributed to an effect on general activity levels. In a recent factor analytic study, we reported that total SAP load on a factor indicating a relationship to defensive or 'cautious' exploration of the arms while the independent loading of head-dipping was consistent with depth exploration [9]. Moreover, systemic administration of alprazolam, a highly potent anxiolytic agent [13], decreased SAP and increased headdipping in mice exposed to the oEPM [9]. Significantly, when displayed in a conventional or standard elevated plus-maze (sEPM), SAP and HD behaviors have been related to risk assessment and, as such, the currently observed changes in these behaviors are entirely consistent with an attenuation of anxiety $[41,42]$. These changes, together with the shift in exploration from proximal to distal areas of the open arms [9], strongly suggest that inactivation of the amygdala with local injection of $\mathrm{CoCl}_{2}$ attenuates approach-avoidance conflict. Present results also corroborate previous studies showing that amygdala lesions reduced the incidence of anxiety-related behavior in rats exposed either to the elevated T-maze $[43,44]$ or the light-dark exploration test $[43,45]$.

Our analysis of the pattern of amygdaloid activation in Experiment 2 showed an increase in Fos-positive labeled cells only in the BLA of oEPM-exposed mice compared to various control conditions. It should be noted that the apparent hemispheric imbalance in the BLA Fos response to oEPM exposure (Fig. 3B) was not statistically significant. However, whereas Fos labelling in the right BLA was significantly increased by oEPM exposure versus all other conditions, it was only increased in the left BLA versus maze-naïve and novelty-exposed mice. The lack of a significant difference in left BLA activation versus the home cage and e-EPM conditions does not however diminish the role of this nucleus in responding to the oEPM. Since the subjects had been thoroughly (daily for 10 days) habituated to the eEPM prior to oEPM exposure, the increase in Fos-positive labeled cells might have simply been due to environmental novelty [46] instead of the aversiveness of the oEPM. However, our results actually showed that exposure to a novel environment led to the opposite effect, i.e. it provoked a reduction in Fos-positive labeled cells in the amygdaloid complex, strongly suggesting that the increased Fos expression in oEPM-exposed mice was not simply due to novelty. It is important to highlight that the currently employed eEPM habituation protocol was necessary in order to minimize the potential confound of acute handling stress that has been reported to be crucial to reduce per se effects on the basal number of Fospositive cells $[29,47]$. However, habituation is stressor specific, such 

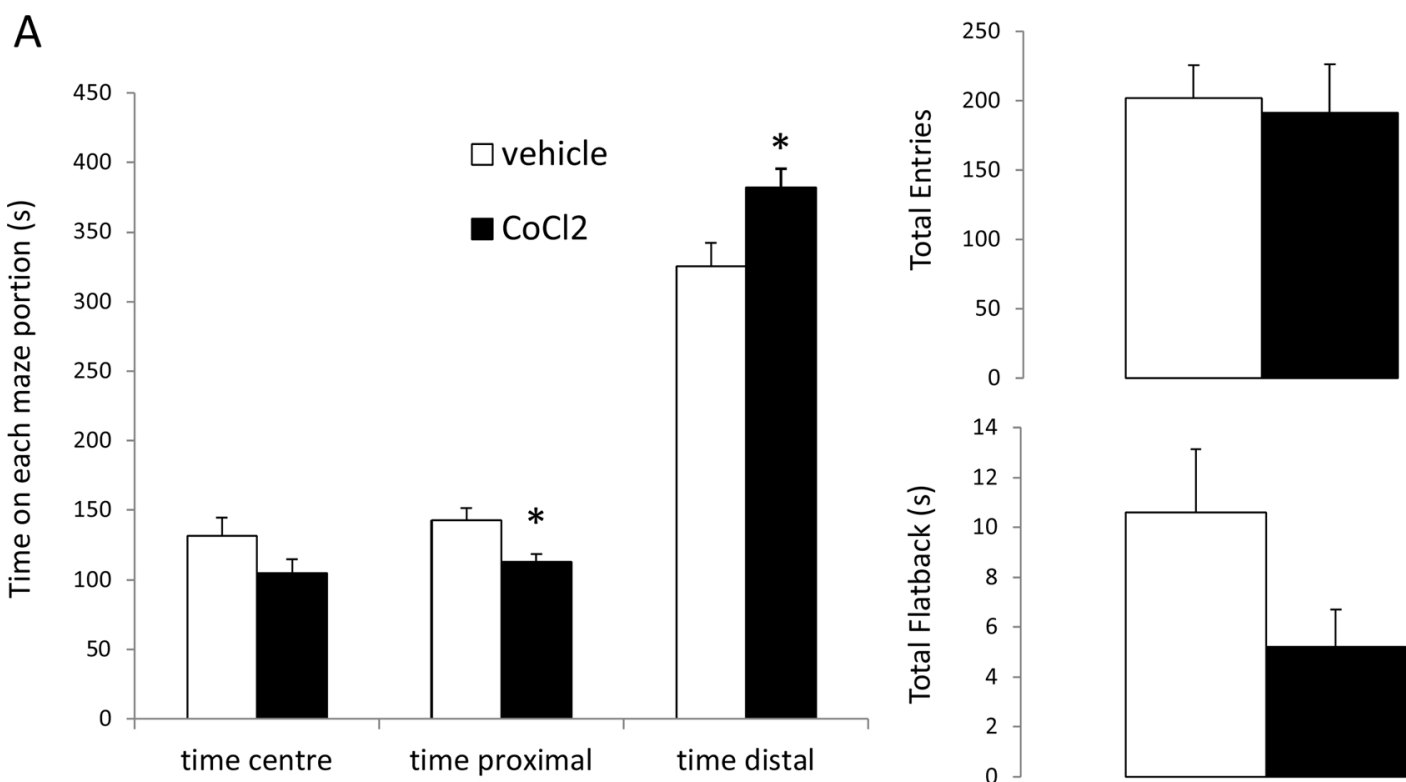

C
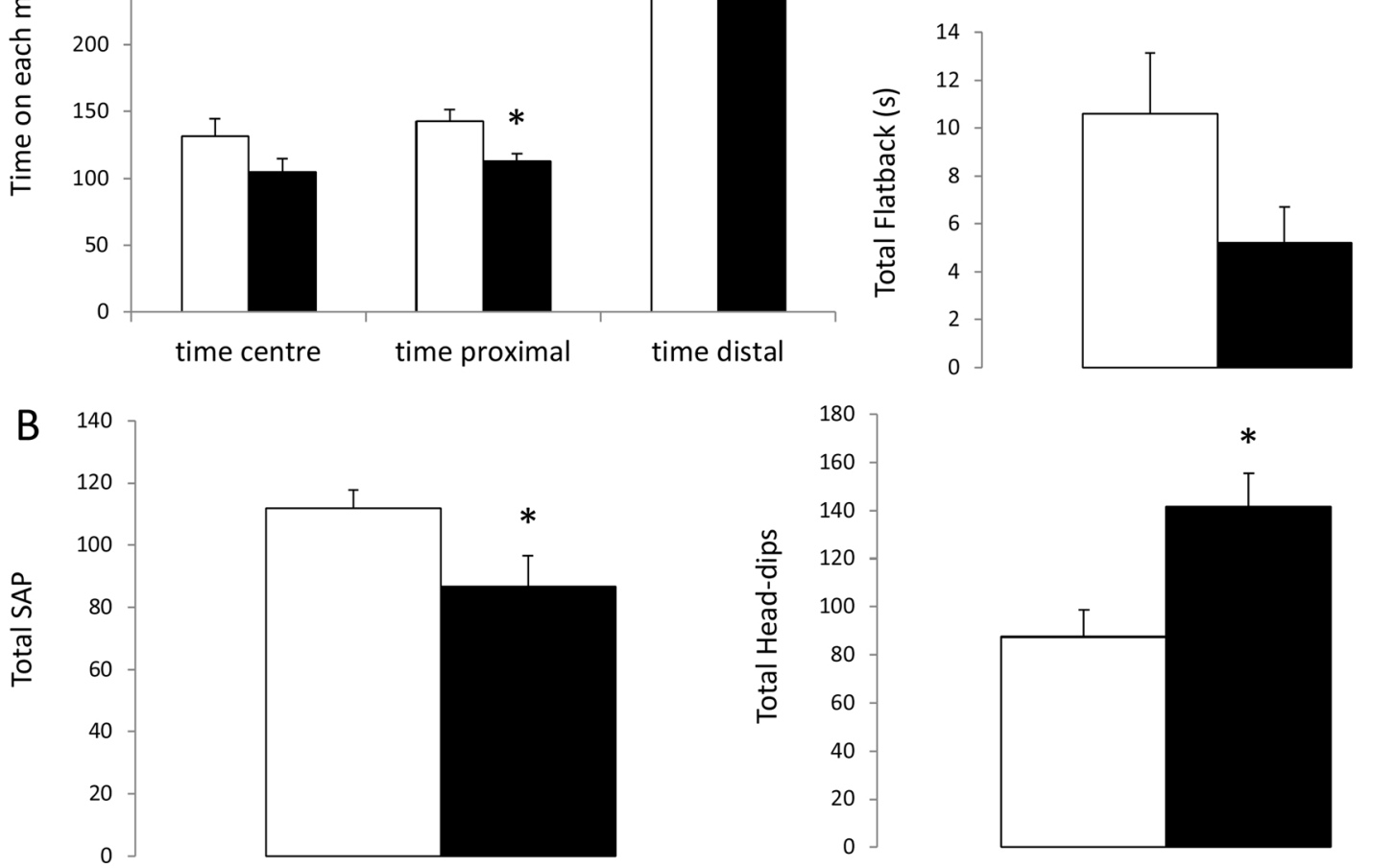

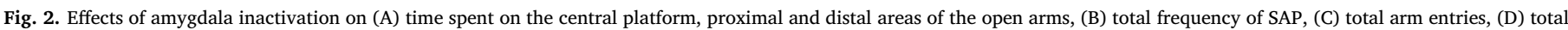
time in flatback approach (s) and (E) total frequency of head-dips. Data are presented as mean \pm S.E.M. $\mathrm{n}=11$ vehicle group; $\mathrm{n}=8 \mathrm{CoCl} \mathrm{l}_{2}$ group. ${ }^{*} \mathrm{p}<0.05$ vs. vehicle group.

that decreased c-fos response to a familiar stressor, does not prevent induction of this gene by a novel stressor [48]. Taken together, it is likely that the increase in Fos-labeled cells within the amygdaloid nuclei is mainly due to the aversiveness of the oEPM. In support of this interpretation, (a) the results of Experiment 1 showed that amygdala inactivation induces an anti-aversive effect in oEPM-exposed mice, (b) the results of Experiment 2 demonstrated that while novelty per se tended to reduce overall Fos expression in the amygdala, it did not significantly alter the number of Fos immiunoreactive cells in either the BLA or CeA, and (c) exposure to the oEPM elicits a stronger plasma corticosterone response than exposure to the eEPM [8].

Present results also show that the magnitude of Fos activation in BLA is distinctly higher (mainly in the right and borderline in the left) in animals exposed to the oEPM when compared to the response of the CeA to the same condition. It is relevant to highlight that the main input nucleus of the amygdala is the BLA, which receives a broad range of sensory input (olfactory, auditory, somatosensory) not only from the thalamus but also the prefrontal cortex which influences decisionmaking and behavioral control through executive outcomes [16,49]. The CeA, in turn, sends outputs to areas that coordinate defensive behaviors through forebrain and brainstem connections [16,49]. While oEPM exposure induced increased Fos activation in both left and right BLA compared to controls, the fact that this was not seen in response to the eEPM suggests that the more aversive a situation the greater the activation of these amygdaloid nuclei. This interpretation is consistent with previous studies showing higher plasma corticosterone levels, a biological marker of stress $[50,51]$, in oEPM-exposed mice compared to
eEPM-exposed mice [8]. The prominent BLA Fos expression suggests that this nucleus is particularly important in the modulation of defensive behavior induced by oEPM exposure, a hypothesis supported by previous findings in rats that exposure to aversive environments (e.g., open field) does not lead to activation of the CeA $[16,46]$ whereas exposure to a conventional EPM results in elevated c-fos expression within the BLA [review: 16]. Taken together, our findings suggest that the aversive experience triggered by oEPM exposure is mostly processed in the BLA, a nucleus closely related to the processing of aversive input $[16,17]$. This functional neuroanatomy may in turn relate to the relative inescapability of the threat posed by the oEPM and hence greater recruitment of defensive neurocircuitry [52].

Although the amygdaloid complex has long been implicated in the neurobiology of fear and anxiety [review: 18], the underlying mechanisms of these emotional states remain to be fully elucidated. For instance, the medial amygdala (MeA) is implicated in the modulation of defensive reactions, since Fos-stained cells in the MeA appear to be related to the emotional novelty of the experimental situation [16].

Furthermore, MeA seems particularly responsive to predator stimuli (e.g. odor) and to coordinate appropriate executive behavior through outputs to the periaqueductal gray [53]. As already noted, the BLA receives and processes sensory information from cortical and thalamic structures, and then transmits to the CeA which, in turn, projects to hypothalamic, midbrain and brainstem effector mechanisms. The BLA also projects directly to the ventral hippocampus (vHIP) and medial prefrontal cortex (mPFC) leading to the exhibition of defensive responses $[16,17,54]$. In addition to reciprocal connections with many 
(A)
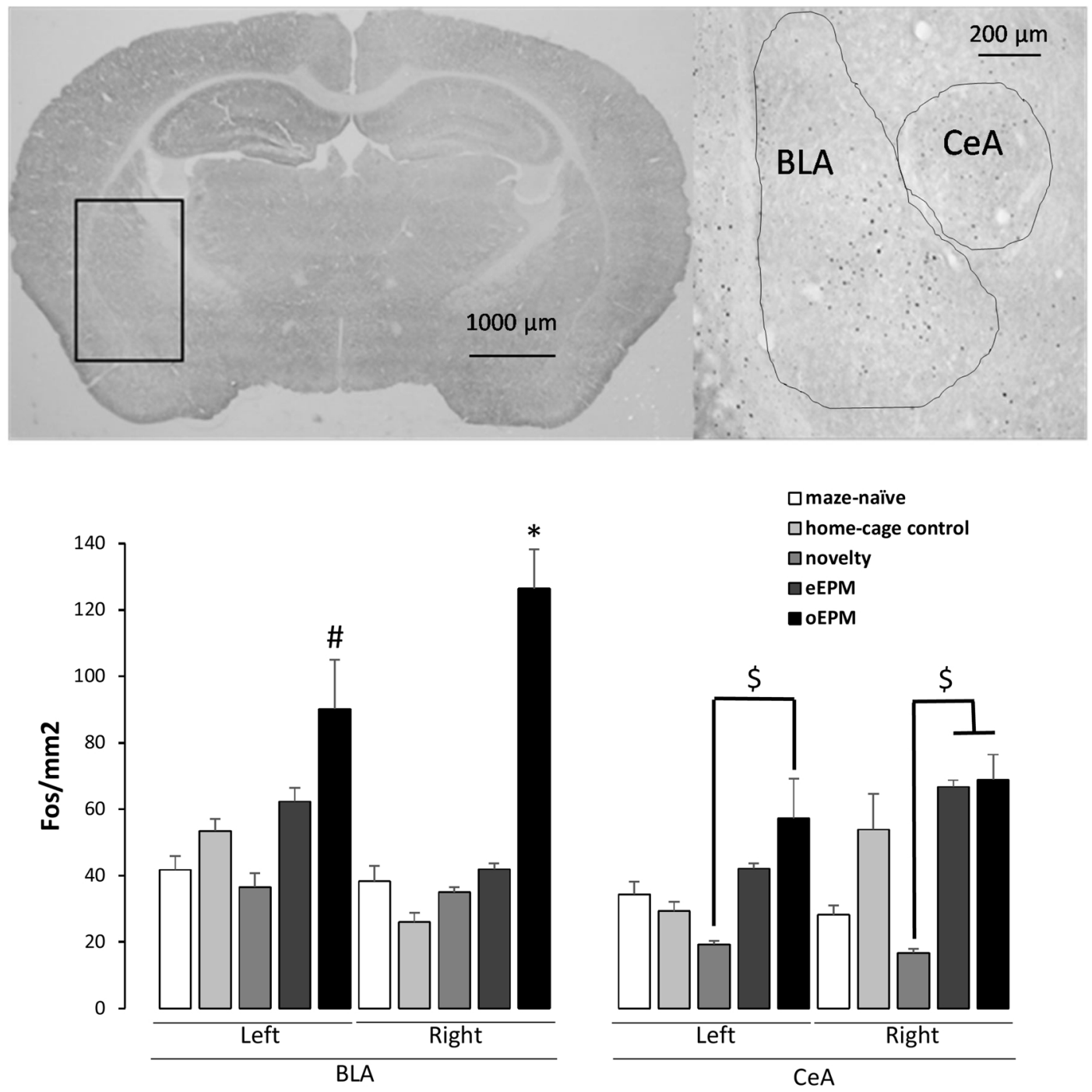

(B)

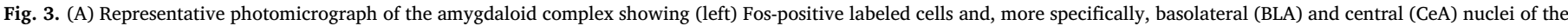

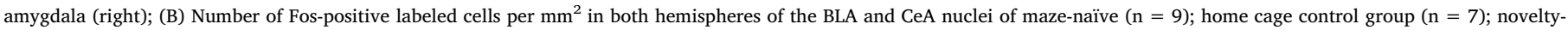

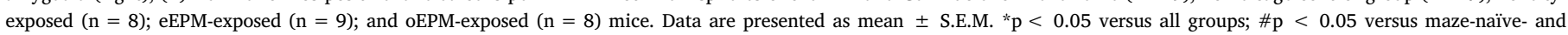
novelty-exposed mice in the left BLA; $\$ \mathrm{p}<0.05$.

regions of the neuraxis, the amygdala displays considerable intra- and inter-nucleus connectivity [16]. Importantly, the functions of these neuronal circuits are determined by their target-specific and/or cellspecific connections. In this context, cell-specific connections within the amygdaloid complex shows that while activation of BLA cells that project to the CeA results in anxiolysis, activation of BLA cells that project to the ventral hippocampus induces anxiogenesis $[16,17,54,55]$. Regarding the BLA-CeA circuitry, clear evidence for an anxiolytic effect was obtained in an optogenetic study [56], corroborating a previous report based on a fear-conditioning paradigm [57]. This points to a functional heterogeneity at the level of BLA cell types or projections suggesting that unconditional paradigms, such as oEPM exposure, might activate the BLA-vHIP, rather than the BLA-CeA, projection. In this context, since BLA-vHIP circuitry was previously reported to be anxiogenic [55], while present results show that amygdala inactivation promoted anxiolytic-like effects in mice exposed to oEPM, we tentatively suggest that this very particular aversive experience may activate the BLA-ventral hippocampal pathway.

In conclusion, our results show that the amygdaloid complex, particularly its basolateral nucleus, plays a significant role in the modulation of defensive behaviors in oEPM-exposed mice. Further studies are needed to clarify whether other limbic areas (e.g., medial prefrontal cortex and ventral hippocampus) also play a role in the modulation of defensive behaviors induced by this type of aversive environment.

\section{Acknowledgements}

We thank Dr. Débora Colombari (Faculdade de Odontologia de Araraquara), Paola Palombo, Paula C. Bianchi, Paulo E. Carneiro and Rodrigo Molini Leão (Laboratório de Química Medicinal e Computacional - USP - São Carlos, SP) for supporting on the imunnohistochemistry assay, and Elisabete Z. P. Lepera, Rosana F. P. Silva and Nathalia Santos Costa for their technical assistance. This study was supported by FAPESP (2013/01283-6), CNPq (478696/2013-2) and PADC/FCF-UNESP. T. Sorregotti, A.C. Cipriano, F.C. Cruz and D.C. Mascarenhas were supported by FAPESP fellowship (Proc. 2014/ 02956-7, 2011/04561-1, 2013/249862, 2013/24986-2 and 2013/ 06764-2) and R.L. Nunes-de-Souza received a CNPq research fellowship (Proc. 306556/2015-4). 


\section{References}

[1] K.F. Campos, V.C. Amaral, J.L. Rico, T.T. Miguel, R.L. Nunes-de-Souza, Ethopharmacological evaluation of the rat exposure test: a prey-predator interaction test, Behav. Brain Res. 240 (2013) 160-170.

[2] L.S. Lester, M.S. Fanselow, Exposure to a cat produces opioid antinociception in rats, Behav. Neurosci. 99 (1985) 756-759.

[3] C.A. Netto, B. Siegfried, I. Izquierdo, Analgesia induced by exposure to a novel environment in rats: effect of concurrent and post-training stressful stimulation, Behav. Neural. Biol. 48 (1987) 304-309.

[4] S. St-Cyr, S. Abuaish, S. Sivanathan, P.O. McGowan, Maternal programming of sexspecific responses to predator odor stress in adult rats, Horm. Behav. 94 (2017) $1-12$.

[5] A.M. Cornélio, R.L. Nunes-de-Souza, Open elevated plus maze- induced antinociception in rats: a non-opioide type of pain inhibition? Physiol. Behav. 96 (2009) 440-447.

[6] R.G. Lister, The use of a plus-maze to measure anxiety in the mouse, Psychopharmacology (Berl.) 92 (1987) 180-185.

[7] E.F. Carvalho-Netto, R.L. Nunes-de-Souza, Use of the elevated T-maze to study anxiety in mice, Behav. Brain Res. 148 (2004) 119-132.

[8] J. Mendes-Gomes, T.T. Miguel, V.C. Amaral, R.L. Nunes-de-Souza, Corticosterone does not change open elevated plus maze-induced antinociception in mice, Horm. Behav. 60 (2011) 408-413.

[9] T. Sorregotti, J. Mendes-Gomes, J.L. Rico, R.J. Rodgers, R.L. Nunes-de-Souza, Ethopharmacological analysis of the open elevated plus-maze in mice, Behav. Brain Res. 246 (2013) 76-85.

[10] T. Sorregotti, Análise etofarmacológica do labirinto em cruz elevado aberto para avaliar comportamentos defensivos e a antinocicepção induzida pelo medo em camundongos. 54 p. Dissertação (Mestrado em Ciências Fisiológicas). Faculdade de Ciências Farmacêuticas, PIPGCF, UFSCar-UNESP, Araraquara (2013) 54.

[11] J. Mendes-Gomes, R.L. Nunes-de-Souza, Concurrent nociceptive stimulation impairs the anxiolytic effect of midazolam injected into the periaqueductal gray in mice, Brain Res. 1047 (2005) 97-104.

[12] J. Mendes-Gomes, R.L. Nunes-de-Souza, Anxiolytic-like effects produced by bilateral lesion of the periaqueductal gray in mice: influence of concurrent nociceptive stimulation, Behav. Brain Res. 203 (2009) 180-187.

[13] G. Chouinard, A. Labonte, R. Fontaine, L. Annable, New concepts in benzodiazepine therapy: rebound anxiety and new indications for the more potent benzodiazepines, Prog. Neuropsychopharmacol. Biol. Psychiatry. 7 (1983) 669-673.

[14] F.G. Graeff, Brain defense systems and anxiety, in: M. Roth, G.D. Burrow, R. Noyes (Eds.), Handbook of Anxiety, vol. 3, Elsevier, New York, 1990, pp. 307-354.

[15] J. Mendes-Gomes, V.C. Amaral, R.L. Nunes-de-Souza, Ventrolateral periaqueductal gray lesion attenuates nociception but does not change anxiety-like indices or fearinduced antinociception in mice, Behav. Brain Res. 219 (2011) 248-253.

[16] E. Knapska, K. Radwanska, T. Werka, L. Kaczmarek, Functional internal complexity of amygdala: focus on gene activity mapping after behavioral training and drugs of abuse, Physiol. Rev. 87 (2007) 1113-1173.

[17] P. Sah, E.S. Faber, M. Lopez de Armentia, J. Power, The amygdaloid complex: anatomy and physiology, Physiol. Rev. 83 (2003) 803-834.

[18] J.B. Rosen, J. Schulkin, From normal fear and pathological anxiety, Psychol. Rev. 105 (1998) 325-350.

[19] S. Tanimoto, T. Nakagawa, Y. Yamauchi, M. Minami, M. Satoh, Differential contributions of the basolateral and central nuclei of the amygdala in the negative affective component of chemical somatic and visceral pains in rats, Eur. J. Neurosc. 18 (2003) 2343-2350.

[20] H.C. Brenhouse, J.R. Stellar, c-Fos and delta FosB expression are differentially altered in distinct subregions of the nucleus accumbens shell in cocaine-sensitized rats, Neuroscience 137 (2006) 773-780.

[21] H.S. Crombag, J.P. Jedynak, K. Redmond, T.E. Robinson, B.T. Hope, Locomotor sensitization to cocaine is associated with increased Fos expression in the accumbens, but not in the caudate, Behav. Brain Res. 136 (2002) 455-462.

[22] A.M. Graybiel, R. Moratalla, H.A. Robertson, Amphetamine and cocaine induce drug-specific activation of the c-fos gene in striosome-matrix compartments and limbic subdivisions of the striatum, Proc. Natl. Acad. Sci. U S A 87 (1990) 6912-6916.

[23] B. Hope, B. Kosofsky, S.E. Hyman, E.J. Nestler, Regulation of immediate early gene expression and AP-1 binding in the rat nucleus accumbens by chronic cocaine, Proc. Natl. Acad. Sci. U. .S A. 89 (1992) 5764-5768.

[24] F.C. Cruz, F. Javier Rubio, B.T. Hope, Using c-fos to study neuronal ensembles in corticostriatal circuitry of addiction, Brain Res. 1628 (2014) 157-173.

[25] G.E. Duncan, D.J. Knapp, G.R. Breese, Neuroanatomical characterization of Fos induction in rat behavioral models of anxiety, Brain Res. 713 (1996) 79-91.

[26] A.M. Linden, M. Baez, M. Bergeron, D.D. Shoepp, Increased c-fos expression in the centromedial nucleus of the thalamus in metabotropic glutamate 8 receptor knockout mice following the elevated plus-maze test, Neuroscience 121 (2003) $167-178$.

[27] N. Salomé, O.D. Salchner, H. Sequeira, A. Wigger, R. Landgraf, N. Singewald, Neurobiological correlates of high (HAB) versus low anxiety-related behavior (LAB): differential Fos expression in HAB and LAB rats, Biol. Psych. 55 (2004) 715-723.

[28] M.C.L. Silveira, G. Sandner, F.G. Graeff, Induction of Fos immunoreactivity in the brain by exposure to the elevated plus-maze, Behav. Brain Res 56 (1993) 115-118.

[29] K.S. Gomes, C.A. Garcia, C.S. Planeta, R.L. Nunes-de-Souza, Fos-like immunoreactivity in central nervous system of mice simultaneously exposed to the elevated plus-maze and nociception, Rev. Bras. Cienc. Farm. 41 (2005) 385-391.

[30] K.B. Baker, J.J. Kim, Amygdalar lateralization in fear conditioning: evidence for greater involvement of the right amygdala, Behav. Neurosci. 118 (2004) 15-23.

[31] D. Baas, A. Aleman, R.S. Kahn, Lateralization of amygdala activation: a systematic review of functional neuroimaging studies, Brain. Res. Rev. 45 (2004) 96-103.

[32] L. Tran, B. Greenwood-Van Meerveld, Lateralized amygdala activation: importance in the regulation of anxiety and pain behavior, Physiol. Behav. 105 (2012) 371-375.

[33] R. Krets, Local cobalt injection: a method to discriminate presynaptic axonal from postsynaptic neuronal activity, J. Neurosc. Methods 11 (1984) 129-135.

[34] N.S. Costa, M.A. Vicente, A.C. Cipriano, T.T. Miguel, R.L. Nunes-de-Souza, Functional lateralization of the medial prefrontal cortex in the modulation of anxiety in mice: left or right? Neuropharmacologymispheric differences between Foslabeled cells 108 (2016) 82-90.

[35] A.A. Scopinho, E.A. Fortaleza, F.M. Corrêa, The medial amygdaloid nucleus is involved in the cardiovascular pathway activated by noradrenaline into the lateral septal area of rats, Eur. J. Neurosci. 36 (2012) 3059-3065.

[36] G. Paxinos, K.B.J. Frankling, The Mouse Brain in Stereotaxic Coordinates, second ed., Academic Press, San Diego, 2001.

[37] A.C. Cipriano, K.S. Gomes, R.L. Nunes-de-Souza, CRF receptor type 1 (but not type 2) located within amygdala plays a role in the modulation of anxiety in mice exposed to elevated plus maze, Horm. Behav. 81 (2016) 59-67.

[38] D.C. Blanchard, R.R. Sakai, B. McEwen, S.M. Weiss, R.J. Blanchard, Subordination stress: behavioural, brain and neuroendocrine correlates, Behav. Brain. Res. 58 (1993) 113-121.

[39] K.G. Borelli, M.L. Brandão, Effects of ovine CRF injections into the dorsomedial, dorsolateral and lateral columns of the periaqueductal gray: a functional role for the dorsomedial column, Horm. Behav. 53 (2008) 40-50.

[40] A. Dalvi, R.J. Rodgers, GABAergic influences on plus-maze behaviour in mice, Psychopharmacology (Berl) 128 (1996) 380-397.

[41] J.C. Cole, R.J. Rodgers, Ethological comparison of the effects of diazepam and acute/chronic imipramine on the behaviour of mice in the elevated plus maze, Pharmacol. Biochem. Behav. 52 (1995) 473-478.

[42] E. Fernandez Espejo, Structure of the mouse behaviour on the elevated plus-maze test of anxiety, Behav. Brain. Res. 86 (1997) 105-112.

[43] C.H. Bueno, H. Zangrossi Jr., M.B. Viana, The inactivation of the basolateral nucleus of the rat amygdala has an anxiolytic effect in the elevated T-maze and light/dark transition tests, Braz. J. Med. Biol. Res. 38 (2005) 1697-1701.

[44] K.C.P. Herdade, C.V.A. Strauss, H. Zangrossi Jr., M.B. Viana, Effects of medial amygdala inactivation on a panic-related behavior, Behav. Brain. Res. 172 (2006) 316-323.

[45] S.B. McHugh, R.M.J. Deacon, J.N.P. Rawlins, D.M. Bannerman, Amygdala and ventral hippocampus contribute differentially to mechanisms of fear and anxiety, Behav. Neurosc. 118 (2004) 63-78.

[46] H.E. Day, A. Badiani, J.M. Uslaner, M.M. Oates, N.M. Vittoz, T.E. Robinson, S.J. Watson Jr., H. Akil, Environmental novelty differentially affects c-fos mRNA expression induced by amphetamine or cocaine in subregions of the bed nucleus of the stria terminalis and amygdala, J. Neurosc. 21 (2001) 732-740.

[47] R.C.R. Martinez, E.F. Carvalho-Netto, V.C.S. Amaral, R.L. Nunes-de-Souza, N.S. Canteras, Investigation of the hypothalamic defensive system in the mouse, Behav. Brain Res. 192 (2008) 185-190.

[48] A.E. Ryabinin, Y. Wang, D.A. Finn, Different levels of fos immunoreactivity after repeated handling and injection stress in two inbread strains of mice, Pharmacol. Biochem. Behav. 63 (1999) 143-151.

[49] V. Neugebauer, Amygdala pain mechanisms, Handb. Exp. Pharmacol. 227 (2015) 261-284.

[50] J.P. Herman, M.M. Ostrander, M.K. Mueller, H. Figueiredo, Limbic system mechanisms of stress regulation: hypothalamo-pituitary-adrenocortical axis, Prog. Neuropsychopharmacol. Biol. Psychiatry 29 (2005) 1201-1213.

[51] S.M. Korte, Corticosteroids in relation to fear, anxiety and psychopathology, Neurosci. Biobehav. Rev. 25 (2001) 117-142.

[52] M.L. Brandão, D.M. Vianna, S. Masson, J. Santos, Organização neural de diferentes tipos de medo e suas implicações na ansiedade, Rev. Bras. Psiquiatr. 25 (2003) $36-41$.

[53] N.S. Canteras, F.G. Graeff, Executive and modulatory neural circuits of defensive reactions: implications for panic disorder, Neurosci. Biobehav. Rev. 3 (2014) 352-364.

[54] P. Tovote, J.P. Fadok, A. Lüthi, Neuronal circuits for fear and anxiety, Nat. Rev. Neurosc. 16 (2015) 317-331.

[55] A.C. Felix-Ortiz, A. Beyeler, C. Seo, C.A. Leppla, C.P. Wildes, K.M. Tye, BLA to vHPC inputs modulate anxiety-related behaviors, Neuron 79 (2013) 658-664.

[56] K.M. Tye, R. Prakash, S.Y. Kim, L.E. Fenno, L. Grosenick, H. Zarabi, K.R. Thompson, V. Gradinaru, C. Ramakrishnan, K. Deisseroth, Amygdala circuitry mediating reversible and bidirectional control of anxiety, Nature 471 (2011) 358-362.

[57] S. Ciocchi, C. Herry, F. Grenier, S.B. Wolff, J.J. Letzkus, I. Vlachos, I. Ehrlich, R. Sprengel, K. Deisseroth, M.B. Stadler, C. Müller, A. Lüthi, Encoding of conditioned fear in central amygdala inhibitory circuits, Nature 468 (2010) 277-282. 